of the University of Pennsylvania in 1836, and in 1839 from the Medical Department, receiving at the same time the degree of Master of Arts. He was President of the Medical Jurisprudence Society in $1866-67$. In 1854 , he was appointed professor of medical chemistry in the old Pennsylvania College, and served for five years. In 1865 , he was elected to the chair of toxicology and medical jurisprudence in the University of Pennsylvania, which he still held at the time of his death. He was the author of several manuals, but his best known work is his text-book on medical jurisprudence and toxicology. He also edited the seventh American edition of Taylor's Medical Jurisprudence.

\section{Women's Medical College of Baltimore.}

To the Editor of the Journal of the american Medical association: In commencing the instruction in Latin of the students of the Woman's Medical College of this city, I gave the following reasons why as medical students they should acquire a knowledge of that language. I am glad to say that all the students of the college except three or four, and they having previously studied it elsewhere, have joined the class.

1. Because though called a "dead" language, and although not now spoken by any nation, it is not really dead, but flourishes with a perennial and ever increasing vigor.

2. Because of its wide and far-reaching influence on the structure and development of the languages of all civilized nations, especially those of Southern Europe.

3. Because the resources of our language do not suffice for the constantly needed new supply of words, for which we are compelled to resort to the "classics."

4. Because we cannot dispense, if we would,with the Latin that has been incorporated into our own language.

5. Because science and medicine are full of Latin terms and others are being constantly added to our scientific vocabulary.

6. Because of the aid it affords to the study of science and medicine and to the knowledge of the source and meaning of words.

7 . Because even an elementary and imperfect knowledge of latin will afford great assistance in your medical studies.

8. Because the study of Latin disciplines the mind, promotes habits of thought and attention, elevates the sentiments, imparts a scholarly tone, and furnishes one with noble examples, grand ideas and a magnificent literature.

9. Because no translation affords an adequate conception of the great classical authors, and besides if it did scarcely anyone would ever read it. Thus those who do not study the language itself are virtually cut off from all its benefits.

10. Because a classical and literary training is the most important preparation for the medical career.

11. Because a very respectable knowledge of Latin can be acquired at very little cost of time and study, perseverance being the chief element of success in its acquisition.

12. Because its requirement is in the line of elevation of the medical standard, and consequently of the standing of the medical profession.

13. Because this college in common with all respectable American medical colleges now requires it as a part of its preliminary requirements, in conformity with the regulations of the American Medical College Association.

14. Because, for the new students, the forms of its requirement are most liberal and accommodating, a year being allowed for preparation.

I1. Because through the liberality of our Faculty the opportunity of acquirement is offered to all of you-whether first, second, third, or fourth year students, free of cost.

Baltimore, Oct. 18, 1892
To the Editor of the Journal of the AMERICan Medical Association:

Having received favorable responses to a letter addressed to all Southern Medical Colleges, we are authorized by them to say that a convention of their representatives will be held in Louisville, Ky., November 16, 1892, for the purpose of considering the question of a higher standard of medical education.

Yours fraternally,

W. T. BRIGGS,

G. C. SAVAGE.

\section{NECROLOGY.}

Dr. John James Reese, of the University of Pennsylvania, died at Atlantic City, early in September. He was a toxicologist of national reputation, and had been identified with jurisprudential medicine and the University since 1865 . He retired to an emeritus professorship in October of last year. He was the American editor of Taylor's seventh edition of the standard treatise on Medical Jurisprudence. He also published a college text-book or Manual of Toxicology, also an analysis of Physiology. In 1861, he served the Government as surgeon of volunteers, and was put in charge of the United States Hospital on Christian street, Philadelphia. He became the visiting physician to St. Joseph's Hospital and two or more other charitable institutions. He was in his seventy-fifth year at the time of his demise; he first joined the American Medical Association early in the fifties.

Dr. Janes Henry Stevart, of Baltimore, died October 8 , in the fifty-eighth year of his age. He was a native of that city, son of the late Gen. George H. Steuart. He was a graduate of Princeton College in 1855, and of the medical department of Maryland University two years later. " $\mathrm{He}$ leaves behind him a monument in the gratitude and love of those to whom his high life and labors were a blessing and an example." His final illness was one of prolonged and patient suffering. A widow and three children survive him.

\section{BOOK REVIEWS.}

The Legends of Alaska. By Prof. Bushrod W. James, M. D. Porter \& Coates, Publishers, Philadelphia.

This exceedingly attractive little volume gives us a glimpse into the peculiarities of the people of Alaska, as well as the natural resources of wealth that are found in that portion of our Nation's domain. The book is made all the more readable by reason of its being written in the style of $\mathrm{Hia}$ watha.

Simple WATER Test.-Into a ground glass stoppered, perfectly clean bottle put five ounces of the water to be tested. To the water add ten grains of pure, granulated, white sugar. Cork tight, and set in a window exposed freely to light but not to direct rays of the sun. Do not disturb the bottle, and keep the temperature as near $70^{\circ} \mathrm{F}$. as possible. If the water contains organic matter, within forty-eight hours, an abundance of whitish specks will be seen floating about, and the more organic matter the more specks. In a week or ten days, if the water is very bad, the odor of rancid butter will be noticed on removing the stopper. The little specks will settle to the bottom, where they appear as white flocculent masses. Such water should not be used for potable purposes. 